Marquette University

e-Publications@Marquette

Chemistry Faculty Research and Publications

Chemistry, Department of

12-1-1999

\title{
TGA/FTIR: An Extremely Useful Technique for Studying Polymer Degradation
}

Charles A. Wilkie

Marquette University, charles.wilkie@marquette.edu

Accepted version. Polymer Degradation and Stability, Vol. 66, No. 3 (December 1999): 301-306. DOI. (C) 1999 Elsevier. Used with permission. 


\section{Marquette University}

\section{e-Publications@Marquette}

\section{Chemisty Faculty Research and Publications/College of Arts and Sciences}

This paper is NOT THE PUBLISHED VERSION; but the author's final, peer-reviewed manuscript. The published version may be accessed by following the link in the citation below.

Polymer Degradation and Stability, Vol. 66, No. 3 (December, 1999): 301-306. DOI. This article is (C) Elsevier and permission has been granted for this version to appear in e-Publications@Marquette. Elsevier does not grant permission for this article to be further copied/distributed or hosted elsewhere without the express permission from Elsevier.

\section{TGA/FTIR: An Extremely Useful Technique for Studying Polymer Degradation}

Charles A. Wilkie

Department of Chemistry, Marquette University, Milwaukee, WI

\section{Abstract}

Thermogravimetric analysis coupled to Fourier transform infrared spectroscopy, TGA/FTIR, has been used to probe the degradation of several polymeric systems. These include poly(methyl methacrylate) in the presence of various additives, graft copolymers of acrylonitrile-butadiene-styrene and styrene-butadiene with sodium methacrylate and styrene with acrylonitrile, blends of styrene-butadiene block copolymers with poly(vinylphosphonic acid) and poly(vinylsulfonic acid), and cross-linked polystyrenes. Additives may interact with poly(methyl methacrylate) by coordination to the carbonyl oxygen to a Lewis acid and the subsequent transfer of an electron from the polymer chain to the metal atom or by the formation of a radical which can trap the degrading radicals before they can undergo further degradation. When an inorganic char-former is graft copolymerized onto a polymer, there is a good correlation between TGA behavior in an inert atmosphere and thermal stability in air, but this is not true when the char is largely carbonific. 


\section{Introduction}

Many techniques have been used to study the thermal degradation of polymers, including pyrolysis mass spectroscopy, thermal volatilization analysis, thermogravimetric analysis, etc. In this paper, some of the work which has been carried out in this department over the past several years using thermogravimetric analysis coupled to Fourier transform infrared spectroscopy, TGA/FTIR will be reviewed, and show that this is one of the most useful techniques that scientists have at their disposal to probe and understand thermal degradation pathways. An advantage of reviewing one's own work is that correlations can be found which were not obvious at the time the work was performed but which are now easily seen. Thus, in addition to reviewing the older work, critical comments on degradation pathways will be provided. TGA/FTIR does not provide answers for all problems and this paper will mention techniques that can be used in conjunction with TGA/FTIR to more fully describe the degradation process.

\section{Experimental}

TGA/FTIR work that has been carried out in this laboratory has utilized two different types of equipment. The earliest work was performed using an Omnitherm horizontal balance TGA instrument interfaced to a Digilab FTS-60 Fourier transform infrared spectrometer. Later work used a Cahn 131 thermogravimetric balance coupled to a Mattson Galaxy infrared spectrometer. The significant difference between these units is that the Omnitherm is a total flow unit, i.e. all of the gases which evolved, together with the purge gas, flowed into the infrared gas cell. On the other hand, the Cahn unit uses a sniffer tube that extends into the sample cup and removes some of the evolved gases along with a portion of the inert gas purge. With the total flow system, one examines all of the gases but the amount of inert gas purge may overpower the total gas pressure and gases may be missed. With the sniffer tube, since the gases are sampled directly from the sample cup, more of the total gas pressure is due to the evolved gas and the result should be more representative of the degradation process.

The preparation of the samples for analysis has been described in the individual papers; the reader should refer to these for experimental details.

\section{Results and discussion}

\subsection{Degradation of poly(methyl methacrylate)}

The degradation of poly(methyl methacrylate), PMMA, has been studied for many years and it is well known that this material degrades by end chain scission and gives a very high yield of monomer ${ }^{[1]}$. The details of the degradation have only recently been elucidated by Kashiwagi et al [2], [3], [4], [5], [6], [7], [8] and Manring [9], [10], [11], [12], [13]. Kashiwagi has shown [4] that the degradation is initiated at end chain unsaturations, weak links, such as head-to-head linkages, and also by random scission. Random scission produces both a primary radical and a tertiary radical 86 . The tertiary radical will facilely depolymerize but the fate of the primary radical is less certain. 
Two schemes have been proposed to account for PMMA degradation; one suggests that the initial step in the degradation is main chain cleavage which is later followed by side chain cleavage ${ }^{[8]}$ while the other supports an initial side chain cleavage ${ }^{[12]}$ followed by main chain cleavage.

The degradation schemes of Kashiwagi and Manring are identical except for the initial step; the significant feature is that the degradation produces both a tertiary radical and a primary radical which undergo subsequent degradation. The tertiary radical degrades by unzipping to give monomer and a new tertiary radical. It is suggested that the primary radical forms a methallyl terminated species which leads to a new tertiary radical. The degradation scheme, following the Kashiwagi pathway, is shown below as Scheme 1.
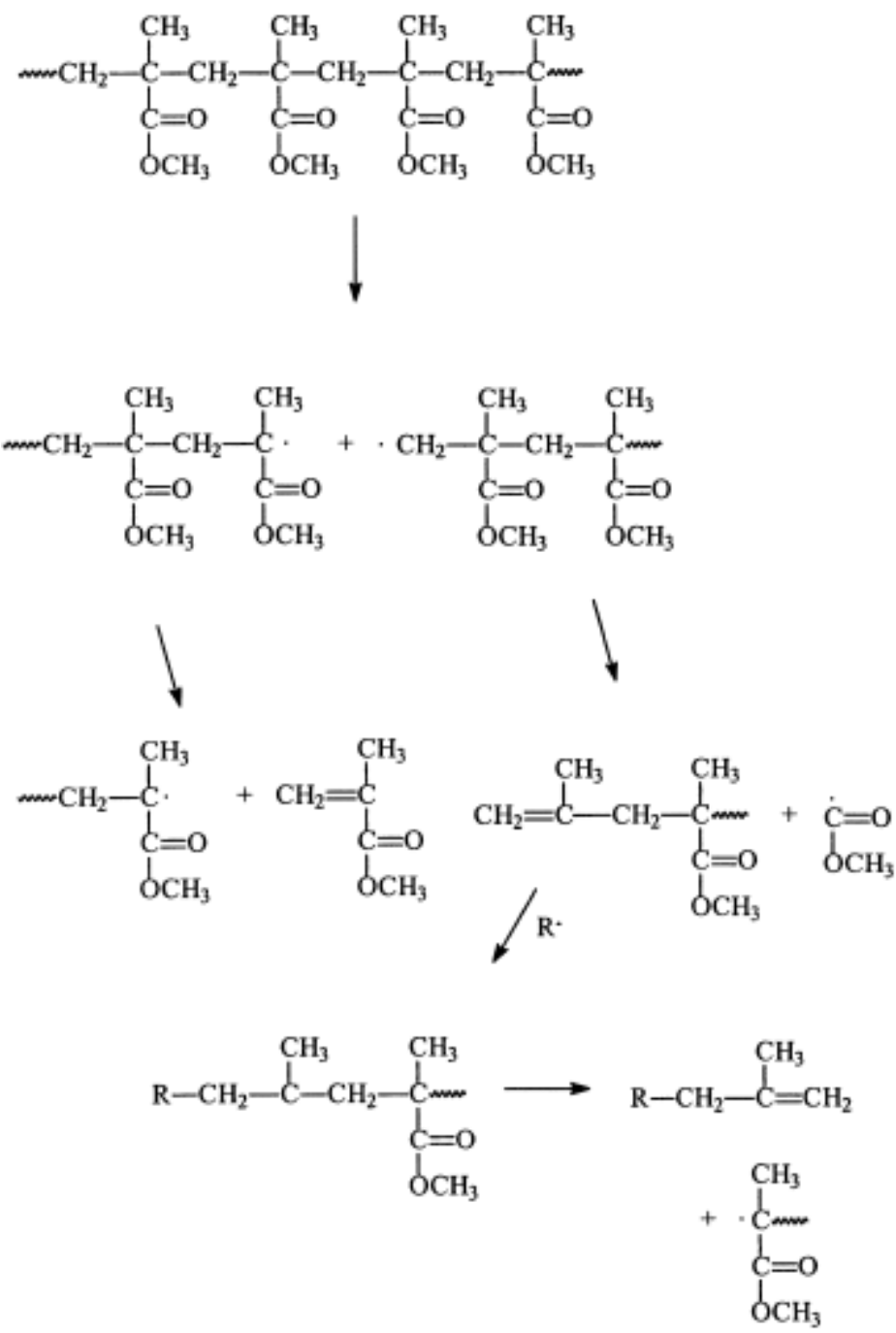

Scheme 1. Degradation pathway of poly(methyl methacrylate).

A significant amount of work has been carried out in these laboratories on the interaction of PMMA with additives; additives which have been examined include red phosphorus [14], [15], Wilkinson's salt, $\left(\mathrm{PPh}_{3}\right)_{3} \mathrm{RhCl}$ [16], [17], $\mathrm{Ph}_{x} \mathrm{SnCl}_{4-\mathrm{x}}(\mathrm{x}=0-4)^{[18],}{ }^{[19]}, \mathrm{Ph}_{2} \mathrm{~S}_{2}{ }^{[20]}$, Nafions ${ }^{[21]}$, various 
transition metal halides [22], [23], [24] and copolymers of MMA with 2-sulfoethylmethacrylate [25]. The focus of this work has been to develop a mechanistic understanding of the effects of the additive on the degradation of the polymer. In order to enhance the thermal stability of the polymer, one must either prevent the initial degradation or capture the products of this degradation so they cannot undergo further reaction.

Kashiwagi ${ }^{44]}$ has shown that PMMA prepared by an anionic process does not contain weak links or end chain unsaturations so the only degradation which occurs is the random scission process. One strategy which may be used to prevent random scission is cross-linking of the polymer chain so that the unzipping reaction is inhibited. This may involve cross-linking of either the undegraded chain or the initially formed radicals. As will be shown below, most additives appear to function in this way. In order to capture the initially formed products it would be necessary to incorporate a very efficient radical scavenger into the system. This process has also been observed in these studies. Since the primary radical facilely produces a new tertiary radical, one must only contend with the capture of the tertiary radical.

The effect of manganese(II) chloride [23], chromium (III) chloride ${ }^{[24]}$, and iron(II) and iron(III) chlorides ${ }^{[22]}$, copper(I) and copper(II) chlorides ${ }^{[22]}$, and nickel(II) chloride ${ }^{[22]}$ on the degradation of PMMA has been examined. The initial step when a transition metal interacts with PMMA has been shown by McNeill [26], [27] to be coordination of the metal ion to the carbonyl oxygen of the polymer. This coordination is a function of the Lewis acidity of the metal ion. For those salts which have been studied, only copper(I) chloride is not a Lewis acid and should not coordinate. This is reflected in the TGA/FTIR data for this combination. There is no difference between the data for virgin polymer and its blend with $\mathrm{CuCl}$. After coordination, depending on the metal chloride bond strength, one may observe methyl chloride. This may arise from a concerted pathway in which the ester is converted into its metal salt. The ease of elimination of methyl chloride depends on the strength of the metal chloride bond. The bond strength is largest for $\mathrm{Ni}^{2+}$ and $\mathrm{Cu}^{2+}$ and methyl chloride is not seen in either case. Methyl chloride evolution is also not observed with $\mathrm{Cr}^{3+}$; this is due to the thermal instability of $\mathrm{CrCl}_{3}$ which is reduced to $\mathrm{CrCl}_{2}$ at elevated temperature [28].

The presence of a transition metal halide coordinated to the carbonyl oxygen may stabilize the polymer, since the free electron may be facilely transferred to the metal ion. The transfer of the electron to the metal ion merely changes the oxidation state of the metal and this should have no effect on the course of the reaction. On the other hand, it also removes the radical site from the polymer chain and, since the polymer cannot degrade in the absence of a radical site, this leads to stabilization of the polymer. TGA/FTIR studies do not show that coordination occurs but they do show that methyl chloride is evolved. One of the limitations of this technique is that one does not sample the solid state but only the vapor phase; one cannot discern the reactions that occur in the solid except by inference from the volatiles that come off from the reaction.

There are several ways in which the TGA/FTIR data may be displayed. These include (1) a tabular display of the mass loss and the gases which are observed in each region; (2) the display of individual spectra at various temperatures; (3) the display of spectra at several temperatures in a stacked plot; and (4) the display of the infrared absorbance for some peak(s) overlaid on the TGA curve. Table 1 shows the evolved gases in each of the three regions of 
mass loss in the TGA curve of a 1:1 blend of PMMA:FeCl3. Fig. 1 shows the stacked plot for the gases which evolve in the temperature region between 260 and $684^{\circ} \mathrm{C}$. In the table one sees all of the data but in the stacked plot one can follow the evolution of the different gases with time and get a better idea of the time profile of the evolution. The evolution of monomer, at $1735 \mathrm{~cm}^{-1}$, begins at about $300^{\circ} \mathrm{C}$ and methanol begins at approximately the same temperature. The evolution of $\mathrm{HCl}$ is not seen until the temperature is above $500^{\circ} \mathrm{C}$.

Table 1. Evolved gases as a function of mass loss in the distinct temperature regions of the degradation of a blend of PMMA and iron (III) chloride

Temperature region, ${ }^{\circ} \mathrm{C} \quad$ Mass loss in this region Evolved gases

$\begin{array}{lll}50-350 & 52 \% & \mathrm{H}_{2} \mathrm{O}, \mathrm{CH}_{3} \mathrm{OH}, \mathrm{MMA}, \mathrm{CH}{ }_{3} \mathrm{Cl} \\ 350-684 & 10 \% & \mathrm{CH}_{3} \mathrm{OH}, \mathrm{MMA}, \mathrm{CH}_{3} \mathrm{Cl}, \mathrm{HCl}, \mathrm{CH}_{4}, \mathrm{CO} \\ \text { Residue } & 38 \% & \end{array}$
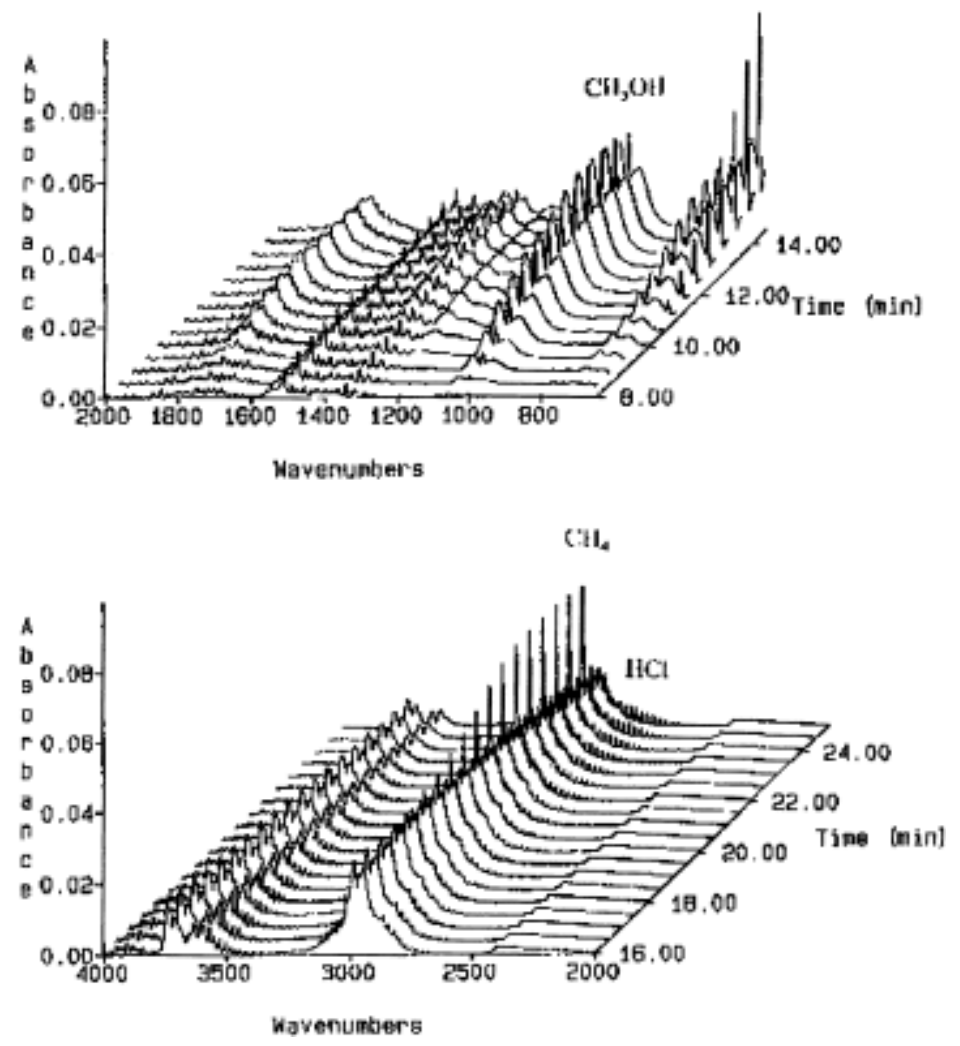

Fig. 1. Evolution of gases as a function of time from a blend of PMMA and iron (III) chloride. A time of 8 min corresponds to a temperature of $160^{\circ} \mathrm{C}$ and the ramp rate was $20^{\circ} \mathrm{C}$ per min.

A different route for stabilization of PMMA was observed in a TGA/FTIR study on the interaction between Nafion- $\mathrm{H}^{\circledR}$ and PMMA ${ }^{[21]}$. In order to understand how these two materials may interact, it is necessary to first determine the differences between the degradation of the pure materials and the blend. The degradation of Nafion leads to the evolution of sulfur dioxide, carbonyl fluorides, and fluorocarbons. When the blend is degraded, neither the carbonyl fluorides nor the fluorocarbons are produced. This suggests that the radical which 
gives rise to these compounds reacts in some different way. It was also observed that the degradation of a blend of these materials degraded in two steps nearly $80^{\circ} \mathrm{C}$ higher than the degradation of PMMA. Both of the components of the blend degrade in this region and both produce radicals. The observed inhibition of degradation is due to radical coupling reactions which lead to stabilization. These radical coupling reactions may involve either main chain cleaved MMA fragments which couple with the Nafion or side chain cleaved material. Stabilization results from the fact that the random scission reaction may now occur at a fluorinated carbon site and this will not depolymerize as easy as at a methylene site.

TGA/FTIR studies on the degradation of PMMA in the presence of additives have disclosed two different pathways by which PMMA may be stabilized. Both of these involve trapping of the species which are formed in the initial degradation; in the presence of coordinated metal halides, and by extension other materials which may coordinate to the carbonyl oxygen, unzipping of the tertiary radical becomes more difficult while with Nafion the tertiary radical is trapped by a Nafion radical. Scheme 2 shows the two pathways by which the tertiary radical from PMMA degradation may be trapped; the absence of a radical on the chain requires a new initiation for the degradation process.<smiles>CCC(C)(CC(C)(C)C(=O)OC)C(=O)OC</smiles>
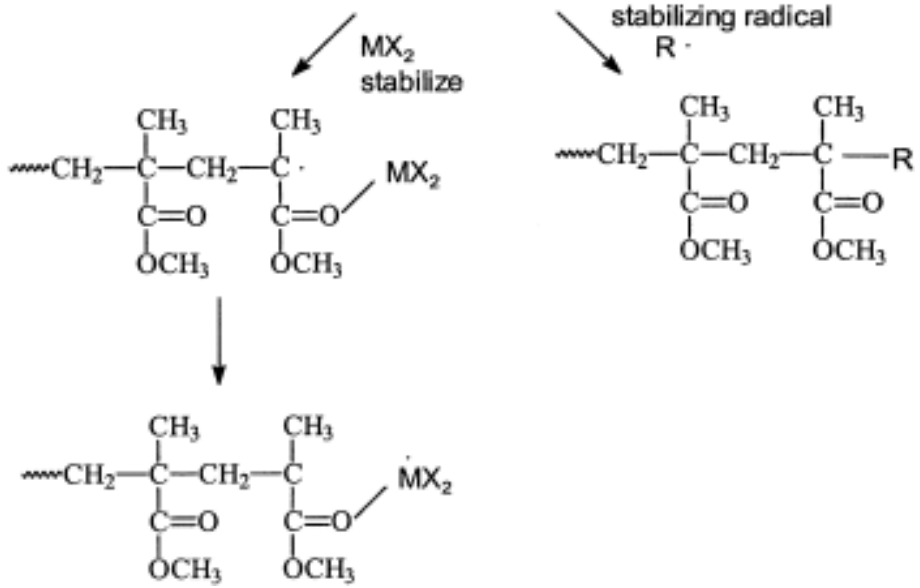

Scheme 2. Stabilization of the tertiary PMMA radical by transition metal halides and by coupling with stabilizing radicals; both remove the radical from the polymer chain.

\subsection{Degradation of butadiene-based graft copolymers}

One area of great interest to this laboratory is the potential for stabilization of polymers by the graft copolymerization of char-formers onto the surface of the polymer. If one hopes to impart thermal stability to the polymer by this process, it is necessary to graft copolymerize a charformer onto the polymer to be protected. We have used sodium methacrylate as the charforming monomer to be grafted since it gives a good yield of sodium carbonate upon 
degradation [29]. Graft copolymerization of this monomer onto three different butadienecontaining polymer, acrylonitrile-butadiene-styrene terpolymer, ABS [30], [31], and two styrenebutadiene copolymers, herein referred to as SBS and K-resin [32], [33]. In both cases reaction occurs by attachment to an allylic position in the butadiene portion of the polymers. The degradation of unmodified $A B S{ }^{[34]}$ commences at about $340^{\circ} \mathrm{C}$ with the evolution of butadiene followed closely by aromatics from the degradation of the styrenic portion of the polymer. The evolution of acrylonitrile does not begin until $400^{\circ} \mathrm{C}$. For the grafted polymer the evolution of aromatics and butadiene begin about $100^{\circ} \mathrm{C}$ higher than in the virgin material and acrylonitrile is never observed. Since the degradation of all portions of the polymer is changed, one may conclude that the graft layer covers the entire polymer. The cone calorimetric study confirms this result through the excellent performance of this material.

When sodium methacrylate is graft copolymerized onto either SBS or K-resin, there is little difference between the graft copolymer and the virgin material in the evolution of volatiles. This suggests that the presence of the graft layer has little effect on the degradation of the polymers. Cone calorimetry again confirms this result. It is of interest that cone calorimetry and TGA/FTIR lead to the same conclusion since it is easier and less expensive to perform the TGA/FTIR experiment than to obtain cone calorimetric results. More work must be performed to confirm the similar nature of these experiments but this may simplify future studies if it is shown to be general.

\subsection{Degradation of styrene-based graft copolymers}

The thermal degradation of polystyrene proceeds by a random scission process [1]; the production of benzene, toluene, styrene, and styrene oligomers begins at about $350^{\circ} \mathrm{C}{ }^{[34]}$. A graft copolymer has been produced by the addition of acrylonitrile onto polystyrene using an anionic copolymerization process [35], [36]. In order to offer thermal protection by a graft copolymerization process, it is necessary that the graft layer degrades first and forms a char which can protect the underlying layer. From the TGA/FTIR study the first product one observes is ammonia which arises from the degradation of polyacrylonitrile. For virgin polyacrylonitrile, ammonia evolution begins at about $290^{\circ} \mathrm{C}$ while in this graft copolymer ammonia evolution does not commence until $350^{\circ} \mathrm{C}$ and the aromatics which are the signature of polystyrene degradation does not begin until $420^{\circ} \mathrm{C}$ which is $70^{\circ} \mathrm{C}$ higher than in virgin polystyrene. Both graft copolymers and blends of polystyrene with polyacrylonitrile show similar behavior. There are two observations of significance here, the degradation of polystyrene begins at higher temperature and the degradation of acrylonitrile begins at higher temperature; each of these will be examined separately.

The higher temperature for the evolution of aromatics indicates an enhanced thermal stability for the graft copolymer. Since the graft layer does degrade initially, one can anticipate that it will form a char layer and offer a thermal barrier so that the underlying polystyrene cannot escape. A similar degradation pathway is seen in blends as in the graft copolymers and this implies that it is not imperative that the char be formed at the surface of the polymer, it is just important that char be formed. Based upon TGA/FTIR results one can conclude that the graft copolymerization of acrylonitrile onto polystyrene does enhance the thermal stability of polystyrene. Unfortunately the cone calorimetry studies do not confirm this result and, in fact, 
they indicate that the graft copolymer as well as blends have a lower thermal stability than virgin polystyrene. This leads to an apparent contradiction since in one case, the graft copolymerization of sodium methacrylate onto ABS, SBS, and K-resin, a good correlation between TGA/FTIR studies under an inert atmosphere and cone calorimetric studies in air is observed, while for poly(styrene-graft-acrylonitrile) there is no correlation. The difference between these lies in the nature of the graft layer. When the graft layer is inorganic, it cannot burn and there will be little difference between nitrogen and air; this is the case for the graft copolymerization of sodium methacrylate. When the graft layer is largely carbonific, it will eventually undergo combustion and there may not be a correlation between studies in air and studies in an inert atmosphere.

In order to understand why the presence of polystyrene should raise the temperature at which polyacrylonitrile begins to degrade, a detailed investigation of the degradation of polyacrylonitrile, PAN [37], was undertaken. It was at this stage that it was realized that TGA/FTIR studies do not enable the complete understanding of a degradation pathway and the solid residues which are produced in the course of the thermolysis were also examined. The solid residues were obtained at temperatures which corresponded to some change in the TGA curve or the appearance of the infrared spectrum of the gaseous products, and at other temperatures based upon these results. The solids were characterized both by elemental analysis and by infrared spectroscopy. From the analysis of the solid residues, one can determine that PAN undergoes a cyclization reaction without any mass loss and that the loss of ammonia occurs from this cyclized product. A complete degradation pathway has been mapped out for PAN based on these results. This pathway states that cyclization occurs through the ends groups of the PAN chain and that this is then followed by tautomerization and aromatization with the elimination of ammonia and hydrogen.

The application of this degradation pathway to poly(styrene-graft-acrylonitrile) permits one to understand the stabilization of the acrylonitrile fragments in the graft copolymer. Degradation of PAN is initiated at the chain ends; the graft copolymer is prepared via an anionic route so the chain ends will be saturated and will not contain functionalities and thus initiation of cyclization will be more difficult and the degradation will occur at higher temperatures.

The above leads one to believe that a material which gives an inorganic char should be more efficacious than an organic char. Accordingly other monomers which have the potential for graft copolymerization have been examined; these include sodium styrenesulfonate, sodium vinylsulfonate, vinylsulfonic acid, and vinylphosphonic acid [38]. All of these materials show a significant volume expansion during the degradation. This intumescent behavior may be of advantage for the stabilization of some polymers. One of the more significant observations in this study is that the TGA curve is essentially the same in either air or an inert atmosphere. As noted above, this is likely due to the production of a largely inorganic residue and lends further credence to the assertion made above on the nature of the residue.

In this study the volatiles have been examined by TGA/FTIR studies and the solid residues have been isolated and examined. This combination permits one to detail a somewhat complete degradation pathway. Perhaps the most significant feature of the degradation process is the production of polyacetylene from the degradation of sodium vinylsulfonate. This 
can facilely aromatize and gives a char which contains both an inorganic and a quite thermally stable organic component. There has been no work as of yet on the graft copolymerization of any of these monomers onto polymers but they offer an exciting possibility if one can develop the necessary technology to enable graft copolymerization.

Studies on blends of poly(sodium vinyl sulfonate) and poly(vinylphosphonic acid) with styrenebutadiene block copolymer have been carried out in order to see if these materials are efficacious. From TGA/FTIR it was found that the blend is more thermally stable as shown by TGA and the evolution of aromatics occurs at a higher temperature. The TGA curves for the virgin polymer and its blend with the poly(vinylphosphonic acid) along with the absorbance of aromatics at $909 \mathrm{~cm}^{-1}$ are shown in Fig. 2.

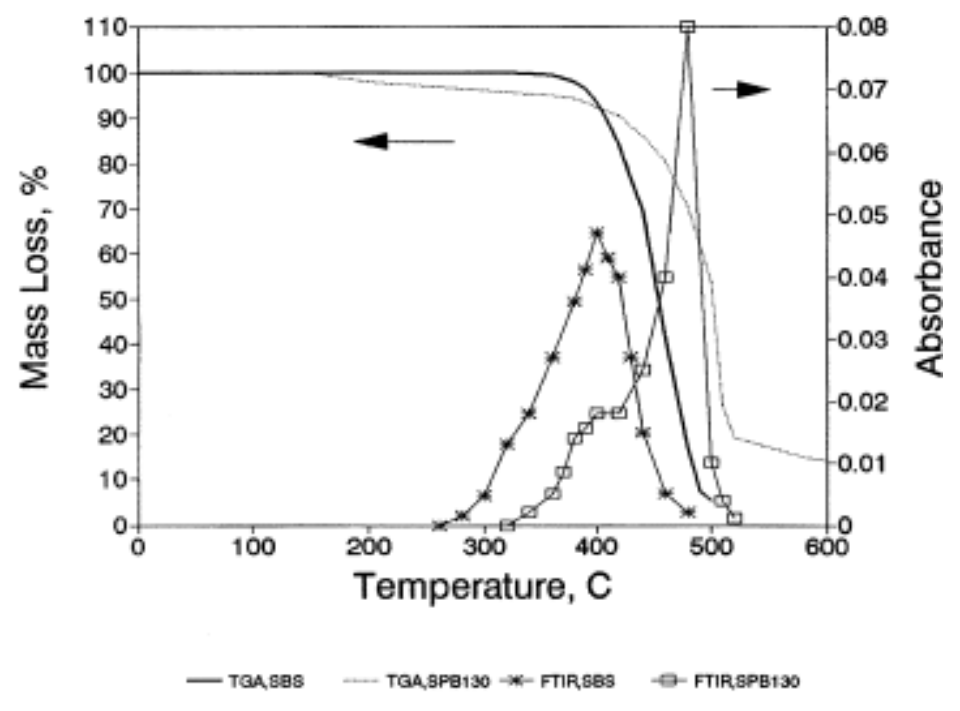

Fig. 2. Composite of TGA curves and infrared absorbance of aromatics at $909 \mathrm{~cm}^{-1}$ for styrene-butadiene block copolymer and its blend with poly(vinylphosphonic acid).

\subsection{How does cross-linking enhance the thermal stability of polymers?}

It is commonly believed that a cross-linked polymer will be inherently more thermally stable than is the correspondingly thermoplastic polymer. Investigations have been carried out comparing the thermal stability of polystyrene and cross-linked styrenes [39], [40], [41] and polybutadiene and its cross-linked relative [42], [43]. Cross-linked polystyrene has been prepared both by Friedel-Crafts chemistry ${ }^{[40]}$ and by the copolymerization of divinylbenzene with styrene [41]. The Friedel-Crafts chemistry is performed on a copolymer of styrene and 4-vinylbenzyl alcohol; catalysts such as transition metal halides and substituted phosphoric acids have been used. In the presence of a suitable catalyst the onset temperature of the degradation is pushed up to $60^{\circ} \mathrm{C}$ higher and the amount of non-volatile residue is greatly increased. From TGA/FTIR studies one can follow the evolution of aromatics from the sample and this occurs at higher temperatures in the cross-linked. Likewise for the copolymers of styrene with divinylbenzene, the evolution of aromatics, the only product observed in the degradation of either the virgin or the cross-linked polymer, begins significantly higher in the cross-linked polymer. 


\section{Conclusion}

The combination of thermogravimetric analysis and Fourier transform infrared spectroscopy provides a very useful tool for the determination of the degradation pathway of a polymer, copolymer, or the combination of one of these with an additive. Since this samples only the vapor phase, it is important to also analyze the solid residue at several temperatures in order to ascertain the correlation between the evolved gases and rearrangements which occur in the solid which permit this evolution.

References

1 Cullis CF, Hirschler MM. The combustion of organic polymers, Oxford: Clarendon Press, 1981. p. 117.

2 T. Kashiwagi, T. Harita, J.E. Brown. Macromolecules, 18 (1985), p. 131.

3 T. Harita, T. Kashiwagi, J.E. Brown. Macromolecules, 18 (1985), p. 1410.

4 T. Kashiwagi, A. Inabi, J.E. Brown, K. Hatada, T. Kitayama, E. Masuda. Macromolecules, 19 (1986), p. 2160.

5 A. Inaba, T. Kashiwagi. Macromolecules, 19 (1986), p. 2412.

6 A. Inaba, T. Kashiwagi, J.E. Brown. Polym Degrad Stab, 21 (1989), p. 1.

7 T. Kitayama, H. Horil, K. Hatada, T. Kashiwagi. Polym Bull, 21 (1989), p. 433.

8 T. Kashiwagi, A. Inaba, A. Hamins. Polym Degrad Stab, 26 (1989), p. 161.

9 Manring, LE. Macromolecules 1988;21:528.

10 Manring, LE. Macromolecules 1989;22:2673.

11 Manring LE. Macromolecules 1989;22:4652.

12 Manring LE. Macromolecules 1991;24:3304.

13 L.E. Manring, W.R. Hentler. Polym Preprints ACS, 34 (1993), p. 118.

14 C.A. Wilkie, J.W. Pettegrew, C.E. Brown. J Polym Sci Polym Lett Ed, 19 (1981), p. 409.

15 C.E. Brown, C.A. Wilkie, J. Smukalla, R.B.Jr. Cody, J.A. Kissinger. J Polym Sci Polym Chem Ed, 24 (1986), p. 1297.

16 S.J. Sirdesai, C.A. Wilkie. J Appl Polym Sci, 37 (1989), p. 863.

17 S.J. Sirdesai, C.A. Wilkie. J Appl Polym Sci, 37 (1989), p. 1595.

18 J.A. Chandrasiri, C.A. Wilkie. Polym Degrad Stab, 45 (1994), p. 83.

19 J.A. Chandrisiri, C.A. Wilkie. Polym Degrad Stab, 45 (1994), p. 91.

20 J.A. Chandrisiri, C.A. Wilkie. Polym Degrad Stab, 46 (1994), p. 275.

21 C.A. Wilkie, J.R. Thomsen, M.L. Mittleman. J Appl Polym Sci, 42 (1991), p. 901.

22 J.A. Chandrasiri, D.E. Roberts, C.A. Wilkie. Polym Degrad Stab, 45 (1994), p. 97.

23 C.A. Wilkie, J.T. Leone, M.L. Mittleman. J Appl Polym Sci, 42 (1991).

24 R.S. Beer, C.A. Wilkie, M.L. Mittleman. J Appl Polym Sci, 46 (1992), p. 1095.

25 S.M. Hurley, M.L. Mittleman, C.A. Wilkie. Polym Degrad Stab, 39 (1992), p. 353.

26 I.C. McNeill, R.C. McGuiness. Polym Degrad Stab, 9 (1984), p. 167.

27 I.C. McNeill, R.C. McGuiness. Polym Degrad Stab, 9 (1984), p. 209.

28 Gmelin L. In: Gmelins Handbuch der Anorganische Chemie, vol. Cr,Pt.B. Berlin, Verlag Chemie, 1962. p.208.

29 I.C. McNeill, M. Zulfiqar. J Polym Sci Polym Chem Ed, 16 (1978), p. 3201. 
30 M. Suzuki, C.A. Wilkie. J Polym Sci: Part A: Polym Chem, 33 (1995), p. 1025.

31 M. Suzuki, C.A. Wilkie. Polym Degrad Stab, 47 (1995), p. 223.

32 X Dong, G. Geuskens, C.A. Wilkie. Eur Polym J, 31 (1995), p. 1165.

33 C.A. Wilkie, M. Suzuki, X. Dong, C. Deacon, J.A. Chandrasiri, T.J. Xue. Polym Degrad Stab, 54 (1996), p. 117.

34 M. Suzuki, C.A. Wilkie. Polym Degrad Stab, 47 (1995), p. 217.

35 T.J. Xue, C.A. Wilkie. J Polym Sci: Part A: Polym Chem, 35 (1997), p. 1275.

36 T.J. Xue, C.A. Wilkie. Polym Degrad Stab, 56 (1997), p. 109.

37 T.J. Xue, M.A. McKinney, C.A. Wilkie. Polym Degrad Stab, 58 (1997), p. 193.

38 Jiang DD, Yao Q, McKinney MA Wilkie CA. Polym Degrad Stab 1999;63:423.

39 J. Li, C.A. Wilkie. Polym Degrad Stab, 57 (1997), p. 293.

40 Wang Z, Jiang DD, McKinney MA, Wilkie CA. Polym Degrad Stab 1999;64:387.

41 Levchik GF, Si K, Levchik SV, Camino G, Wilkie CA. 1999;65:395.

42 Schnabel W, Levchik GF, Wilkie CA, Jiang DD, Levchik SV. Polym Degrad Stab 1999;63:365.

43 Jiang DD, Levchik GF, Levchik SV, Schnabel W, Wilkie CA. 1999;65:387. 